Textures and Microstructures, 1988, Vols. 8 \& 9, pp. 3-6

Reprints available directly from the publisher

Photocopying permitted by license only

(C) 1988 Gordon and Breach Science Publishers Inc.

Printed in the United Kingdom

\title{
In Memoriam Günter Wassermann
}

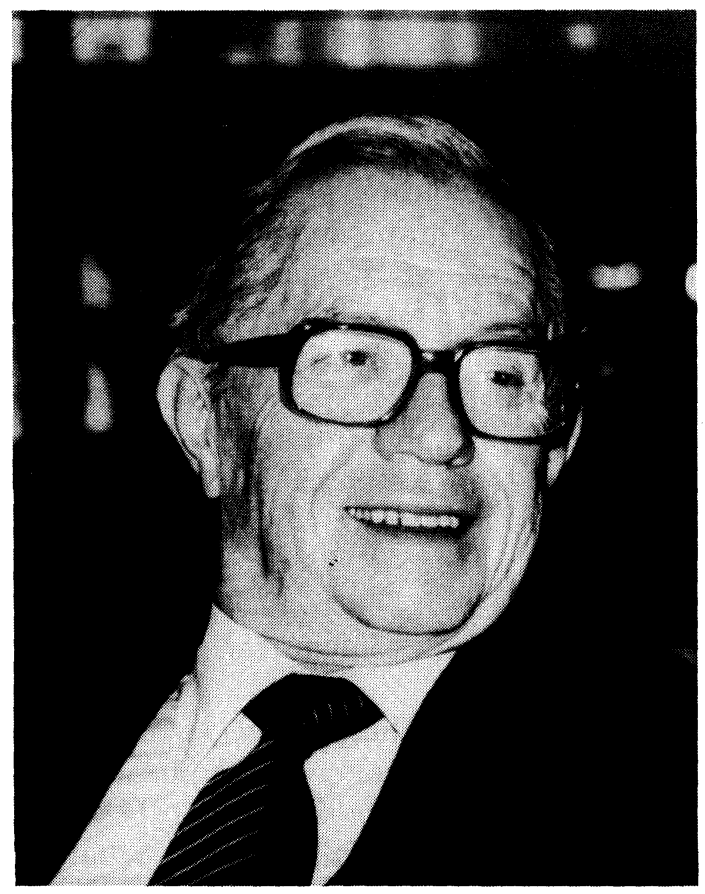

Prof. (em.) Dr. phil. habil. Dr.-Ing. E.h. Günter Wassermann died on September 30, 1986 at the age of 84. In him, we lose the initiator and most prominent representative of the field of textures and the first editor of this journal. His book "Texturen metallischer Werkstoffe" (1939) summarized for the first time what was then known about crystal orientation and its influence on the physical 
properties of polycrystalline materials and thus established a new branch in materials science and technology. The second edition of this book published together with his longstanding co-worker $\mathbf{J}$. Grewen (1962), is still considered the comprehensive standard and reference work of the field of textures. Professor Wassermann was also the initiator of the series of international texture conferences which are now being held periodically under the name of ICOTOM.

Günter Wassermann was born on September 29, 1902 in Berlin. After finishing high-school he studied chemistry at the University of Berlin. In 1924 he started his career at the Kaiser-Wilhelm Institut of Fibre Chemistry at Berlin Dahlem. There, he worked under the guidance of E. Schmid, with whom he was to establish a lifelong friendship. E. Schmid introduced the young chemist to the new and rapidly developing field of metal physics, particularly the plasticity of metal crystals. In his thesis he investigated the structure and mechanical properties of tellurium crystals. This early acquaintance with the crystallographic point of view became determinative for his further multifarious work in physical metallurgy especially the various aspects of crystal orientation in polycrystals.

In 1926 G. Wassermann followed E. Schmid to the Central Laboratory of the Metallgesellschaft at Frankfurt. He subsequently worked at the Kaiser-Wilhelm Institute for Metals in Berlin, KaiserWilhelm Institute for Iron Research at Düsseldorf, the Siemens Central Laboratory and once more the Metallgesellschaft at Frankfurt. It was particularly the comprehensive metallurgical research program of this laboratory which incited Wassermann's broad interest in so many different problems ranging over the whole field of metallurgy.

In 1936 he took his Dr. habil. degree at Berlin and became a lecturer at the Technical University of Darmstadt in 1942. Shortly before the end of the second world war in 1944 he was appointed professor at the University of Mining and Metallurgy at Clausthal (now the Technical University of Clausthal) where he took over the chair of physical metallurgy succeeding Alois Merz.

In the quarter of a century to follow, Günter Wassermann worked as a researcher and academic teacher at Clausthal and developed the department of physical metallurgy from its rather modest initial state after the war to an efficient and well-known institution. He presided over the University as the elected Rector in 
the period of 1948-1950. In 1970 he formally retired but still remained head of the department until 1976 when, at the age of 74, he handed over the responsibilities to his successor. Even thereafter he did not retire from active research work virtually until his death.

Günter Wassermann was a physical metallurgist with a very broad field of interest. Although he became best known for his many activities in the field of texture, he also worked successfully in several other areas. Since his thesis, which dealt with the relationship between crystal structure and mechanical properties of tellurium single crystals, it was always the crystallographic aspect of physical metallurgy that attracted his interest. At that time, this point of view was by no means generally accepted, since metallurgy was usually viewed from the standpoint of chemical composition. In the forword of his book in 1939 Wassermann emphasized that the majority of metallurgists were still opposed to everything related to metal crystals. If the importance of crystal structure as a basis of metal properties is now no longer questioned, Wassermann's work has certainly contributed thereto.

In his Frankfurt time and later on at Clausthal, Wassermann studied the mechanism of precipitation hardening in aluminiumcopper, as well as other alloys. The hardening effect was related to the precipitation of a metastable phase, the structure of which could be determined by $x$-ray diffraction.

A second field of work, he followed over many years, was martensitic transformation studied mainly in iron-nickel and other alloys. He established an orientation relationship between austenitic and martensitic phase known today as the Nishiyama-Wassermann relationship. Together with his co-workers and students he also studied transformation plasticity as a basis of the currently so important shape memory effects.

Mechanical twinning was another effect studied by Wassermann. Like martensite transformation, the crystallographic aspect is also evident here. Earlier investigations in hexagonal metal crystals such as zinc, magnesium, cadmium and cobalt were followed later on by those on brass and other fcc metals of low stacking-fault energy. Wassermann's theory of twinning as the reason for the different rolling and drawing textures (brass type textures) of these metals compared with the copper-type texture of the high stacking-fault energy metals, is generally accepted, today. 
Again stimulated during his Frankfurt time, powder metallurgy became a favourite subject in Professor Wassermann's work. Starting from powder metallurgy of aluminium, subsequently all kinds of powder-metallurgically prepared composite materials were studied. Powder metallurgy allows an easy production of all kinds of composites by "mechanical alloying", even far from thermodynamical equilibrium, including metal-metal, metal-inorganic, and even metal-polymer combinations. The starting point of these investigations was the question of co-deformation of materials of different crystal structure such as fcc, bcc, hcp metal components and even more complex structures in the non-metals. The high deformation which can be achieved in these composites by rolling or drawing leads to a fibrous structure with fibre diameters as small as a few nanometers. Materials of such kind contain an extremely high phase boundary area which, together with the small diameter of the phases themselves, gives rise to many anomalous properties of this class of materials. Although the beginning of this branch of his work dates back to his Frankfurt time, it was essentially after his retirement that Professor Wassermann engaged himself most actively in this exciting new field of work.

Günter Wassermann worked in metallurgy as an academic teacher and scientist for more than fifty years. Many of his students are now well-known themselves, continuing their teacher's work in research and practice. He received many honours such as the honorary membership of the German as well as the Japanese Society of metals, he was honorary citizen of the TU Clausthal and honorary doctor of the Technical University of Aachen.

With the passing of Professor Wassermann the texture community loses its best-known representative, its "great old man" and this journal loses its first editor. And all who had the privilege of his acquaintance have lost a good friend.

H. J. BUNGE 